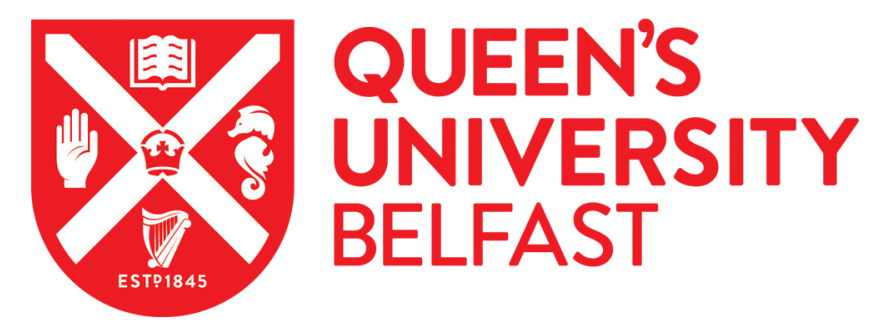

\title{
Long-Term Follow-Up of a Large Active Surveillance Cohort of Patients With Prostate Cancer
}

Klotz, L., Vesprini, D., Sethukavalan, P., Jethava, V., Zhang, L., Jain, S., Yamamoto, T., Mamedov, A., \& Loblaw, A. (2015). Long-Term Follow-Up of a Large Active Surveillance Cohort of Patients With Prostate Cancer. Journal of Clinical Oncology, 33(3), 272-277. https://doi.org/10.1200/JCO.2014.55.1192

Published in:

Journal of Clinical Oncology

Document Version:

Publisher's PDF, also known as Version of record

Queen's University Belfast - Research Portal:

Link to publication record in Queen's University Belfast Research Portal

Publisher rights

(C) 2014 by American Society of Clinical Oncology.

This work is made available online in accordance with the publisher's policies. Please refer to any applicable terms of use of the publisher.

\section{General rights}

Copyright for the publications made accessible via the Queen's University Belfast Research Portal is retained by the author(s) and / or other copyright owners and it is a condition of accessing these publications that users recognise and abide by the legal requirements associated with these rights.

Take down policy

The Research Portal is Queen's institutional repository that provides access to Queen's research output. Every effort has been made to ensure that content in the Research Portal does not infringe any person's rights, or applicable UK laws. If you discover content in the Research Portal that you believe breaches copyright or violates any law, please contact openaccess@qub.ac.uk. 
Laurence Klotz, Danny Vesprini, Perakaa Sethukavalan, Vibhuti Jethava, Liying Zhang, Suneil Jain, Toshihiro Yamamoto, and Andrew Loblaw, Sunnybrook Health Sciences Centre, University of Toronto; and Alexandre Mamedov, Odette Cancer Centre, Sunnybrook Health Sciences Centre, University of Toronto, Toronto, Ontario, Canada.

Published online ahead of print at www.jco.org on December 15, 2014.

Supported by a grant from the Prostate Cancer Research Foundation of Canada

Terms in blue are defined in the glossary, found at the end of this article and online at www.jco.org.

Authors' disclosures of potential conflicts of interest are found in the article online at www.jco.org. Author contributions are found at the end of this article.

Corresponding author: Laurence Klotz, MD, FRCSC, Sunnybrook Health

Sciences Centre, 2075 Bayview Ave, \#MG408, Toronto, Ontario, Canada M4N 3M5; e-mail: Laurence.klotz@ sunnybrook.ca

C 2014 by American Society of Clinical Oncology

0732-183X/15/3303w-272w/\$20.00 DOI: $10.1200 / J C O .2014 .55 .1192$

\section{Long-Term Follow-Up of a Large Active Surveillance Cohort of Patients With Prostate Cancer}

Laurence Klotz, Danny Vesprini, Perakaa Sethukavalan, Vibhuti Jethava, Liying Zhang, Suneil Jain, Toshihiro Yamamoto, Alexandre Mamedov, and Andrew Loblaw

See accompanying editorial on page 238

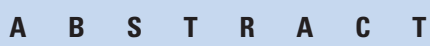

\section{Purpose}

Active surveillance is increasingly accepted as a treatment option for favorable-risk prostate cancer. Long-term follow-up has been lacking. In this study, we report the long-term outcome of a large active surveillance protocol in men with favorable-risk prostate cancer.

\section{Patients and Methods}

In a prospective single-arm cohort study carried out at a single academic health sciences center, 993 men with favorable- or intermediate-risk prostate cancer were managed with an initial expectant approach. Intervention was offered for a prostate-specific antigen (PSA) doubling time of less than 3 years, Gleason score progression, or unequivocal clinical progression. Main outcome measures were overall and diseasespecific survival, rate of treatment, and PSA failure rate in the treated patients.

\section{Results}

Among the 819 survivors, the median follow-up time from the first biopsy is 6.4 years (range, 0.2 to 19.8 years). One hundred forty-nine (15\%) of 993 patients died, and 844 patients are alive (censored rate, 85.0\%). There were 15 deaths (1.5\%) from prostate cancer. The 10- and 15-year actuarial cause-specific survival rates were $98.1 \%$ and $94.3 \%$, respectively. An additional 13 patients $(1.3 \%)$ developed metastatic disease and are alive with confirmed metastases $(n=9)$ or have died of other causes $(n=4)$. At 5,10 , and 15 years, $75.7 \%, 63.5 \%$, and $55.0 \%$ of patients remained untreated and on surveillance. The cumulative hazard ratio for nonprostate-to-prostate cancer mortality was 9.2:1.

\section{Conclusion}

Active surveillance for favorable-risk prostate cancer is feasible and seems safe in the 15-year time frame. In our cohort, $2.8 \%$ of patients have developed metastatic disease, and $1.5 \%$ have died of prostate cancer. This mortality rate is consistent with expected mortality in favorable-risk patients managed with initial definitive intervention.

\section{J Clin Oncol 33:272-277. (C) 2014 by American Society of Clinical Oncology}

\section{INTRODUCTION}

Active surveillance for favorable-risk localized prostate cancer may reduce the risk of overtreatment of clinically insignificant prostate cancer while retaining the option of definitive therapy for patients who are reclassified over time as higher risk.

Beginning in 1995, we initiated a prospective clinical trial to evaluate active surveillance, in which the decision to intervene was determined by prostate-specific antigen (PSA) kinetics and/or histologic progression. Our initial cohort was first reported in 2002, ${ }^{1,2}$ and a follow-up was reported in 2010 of 450 patients with 8 -year follow-up. ${ }^{3}$ This report represents a reanalysis with 993 patients and up to 16 years of follow-up.

\section{PATIENTS AND METHODS}

A prospective, single-arm cohort study was initiated in November 1995 to assess the feasibility of an observation protocol with selective delayed intervention using PSA kinetics and/or histologic progression as triggers for intervention. Favorable and selected intermediate-risk patients were offered an initial surveillance approach. PSA was performed every 3 months for 2 years and then every 6 months in stable patients. A confirmatory biopsy was performed within 12 months of the initial biopsy and then every 3 to 4 years until the patient reached 80 years old. Biopsies were performed according to the Vienna nomogram. ${ }^{4}$ Patients were reclassified as higher risk and offered radical intervention if they met the following criteria:

PSA doubling time (DT) of less than 3 years (from 1996 to 2008). Beginning in 2009, adverse PSA kinetics were discontinued as a sole trigger for intervention; rather, 
they were an indication for closer scrutiny, either with repeat biopsies or a multiparametric magnetic resonance imaging (MRI).

Histologic upgrade on repeat prostate biopsy. Patients had an eight- to 14-core biopsy within a year after the initial biopsy. This targeted the site of the original positive core and the anterior and anterolateral zones. Subsequent biopsies were performed every 3 to 4 years.

Clinical progression as defined by development of an unequivocal palpable nodule during surveillance confirmed histologically to be disease progression.

Between 1995 and 1999, the study was offered to all low-risk patients (Gleason score $\leq 6$ and PSA $\leq 10 \mathrm{ng} / \mathrm{mL}$ ) and to patients older than age 70 years with PSA $\leq 15 \mathrm{ng} / \mathrm{mL}$ or Gleason score $\leq 3+4$ (7). Since January 2000, the study was restricted to low-risk patients (Gleason score $\leq 6$ and PSA $\leq 10$ $\mathrm{ng} / \mathrm{mL}$ ) or patients with favorable intermediate-risk disease (PSA 10 to 20 $\mathrm{ng} / \mathrm{mL}$ and/or Gleason score 3+4) with significant comorbidities and a life expectancy of less than 10 years. The phase II clinical trial was approval by the Sunnybrook Research Ethics Board. From 1995 to 2002, informed consent was obtained from each participant. Beginning in 2003, active surveillance was offered as a management option to patients without a formal consent form. The same data were collected prospectively (also approved by the Research Ethics Board).

\section{Statistical Methods}

Survival analysis was performed in all patients, including Kaplan-Meier overall survival (OS), cause-specific survival (CSS), time to stopping surveillance, and time to PSA failure. Median follow-up time was calculated using the reverse Kaplan-Meier method. ${ }^{5}$ PSA failure was defined as a PSA more than $0.2 \mathrm{ng} / \mathrm{mL}$ after surgery and PSA nadir plus $2 \mathrm{ng} / \mathrm{mL}$ after radiation.

PSA DT was calculated using the general linear mixed model method. ${ }^{6}$ The Hosmer-Lemeshow test was performed for goodness-of-fit. Internal validation of the two final multivariable models was performed using the nonparametric bootstrap method.

\section{RESULTS}

\section{Patient Population}

The current cohort (data lock was May 5, 2013) comprises 993 patients. Median age is 67.8 years (range, 41 to 89 years). Two hundred six patients have been observed for more than 10 years and 50 patients for more than 15 years. Among all 993 patients, 149 died, 819 were alive, and $25(2.5 \%)$ were lost to follow-up. The median follow-up time from the initial cancer diagnosis is 6.4 years (range, 0.2 to 19.8 years). Ten percent of patients were entered onto the study within the previous 2 years.

The distribution of patients by stage, grade, and PSA is shown in Appendix Table A1 (online only) and Table 1. Five percent of patients were diagnosed after a transurethral resection of the prostate, $74 \%$ had T1c disease, $17 \%$ had a palpable nodule, and $4 \%$ were classified as having unknown stage. Baseline PSA was less than $2.5 \mathrm{ng} / \mathrm{mL}$ in $14 \%$, 2.5 to $5 \mathrm{ng} / \mathrm{mL}$ in $30 \%, 5$ to $10 \mathrm{ng} / \mathrm{mL}$ in $43 \%$, greater than $10 \mathrm{ng} / \mathrm{mL}$ in $11 \%$, and unknown in $2 \%$ of patients. Eighty-four percent of patients had a Gleason score of $\leq 6$, and $13 \%$ had a Gleason score of 7 $(3+4)$. Baseline Gleason score could not be ascertained in $2 \%$ of patients (whose original biopsies were performed outside of our institution $>10$ years ago). Twenty-one percent of patients were intermediate risk, of whom 3\% had both PSA more than $10 \mathrm{ng} / \mathrm{mL}$ and Gleason score of 7 .

\section{Mortality Outcomes}

OS is shown in Figure 1. Among 993 patients, 149 patients (15\%) died, and 844 patients were alive (censored rate, $85 \%$ ). The OS range was 0.2 to 20.2 years. The 10 - and 15 -year OS rates were $80 \%$ and $62 \%$, respectively. In univariable and multivariable Cox proportional hazards regression analyses, four significant predictive factors at baseline were found and remained in the multivariable model, namely, age $\geq$ 70 years (hazard ratio [HR], 2.87; 95\% CI, 1.88 to 4.38 ; $P<.001$ ), transrectal ultrasonography volume (HR, $0.983 ; 95 \% \mathrm{CI}, 0.973$ to 0.993; $P=.001)$, Gleason score more than $6(\mathrm{HR}, 1.70 ; 95 \% \mathrm{CI}, 1.14$ to $2.55 ; P=.010$ ), and PSA values (log scale; HR, 1.52; 95\% CI, 1.00 to $2.31 ; P=.048)$.

CSS is shown in Figure 2. Among 993 patients, there were 15 deaths $(1.5 \%)$ from prostate cancer, and 978 patients were alive or suffered death from other causes. All 15 patients who died of prostate cancer had confirmed metastases before death. An additional 13 patients $(1.3 \%)$ with confirmed metastases are alive $(n=9)$ or died of well-documented other causes $(n=4)$. Thus, $2.8 \%(n=28)$ of the entire cohort has developed metastatic disease. Median follow-up time for the patients with metastatic disease was 9.6 years (range, 2.3 to 16.4 years). Median time to metastasis was 7.3 years (95\% CI, 5.81 to 8.76 years). Twelve (44\%) of the 28 patients with metastases had a Gleason score of $3+4(7)$ at diagnosis ( $v 13 \%$ of the overall cohort). Seven patients (26\%) fulfilled Epstein criteria for very low risk.

Of the 15 patients who died of prostate cancer, seven patients received radiotherapy (RT), two had a radical prostatectomy (RP), four received androgen-deprivation therapy as sole therapy, and two refused treatment until metastatic disease developed. The 10- and 15-year actuarial CSS rates were $98 \%$, and $94 \%$, respectively. CSS did not differ between patients less than or greater than age 70 years (Appendix Fig A1, online only; $P=.18$ ). Only two of 28 patients who developed metastasis were not upgraded to Gleason score $\geq 7$ before developing metastatic disease. Neither of these two patients had surgical grading.

\begin{tabular}{|c|c|c|c|c|c|c|c|c|c|c|c|c|c|c|c|c|c|c|}
\hline \multirow[b]{2}{*}{ Gleason Score } & \multicolumn{2}{|c|}{$\begin{array}{l}0 \text { to } 2.5 \\
\mathrm{ng} / \mathrm{mL}\end{array}$} & \multicolumn{2}{|c|}{$\begin{array}{c}>2.5 \text { to } 5 \\
\mathrm{ng} / \mathrm{mL}\end{array}$} & \multicolumn{2}{|c|}{$\begin{array}{c}>5 \text { to } 10 \\
\mathrm{ng} / \mathrm{mL}\end{array}$} & \multicolumn{2}{|c|}{$\begin{array}{c}>10 \text { to } \\
15 \mathrm{ng} / \mathrm{mL}\end{array}$} & \multicolumn{2}{|c|}{$\begin{array}{c}>15 \mathrm{ng} / \\
\mathrm{mL}\end{array}$} & \multicolumn{2}{|c|}{ Unknown } & \multicolumn{2}{|c|}{ Total } & \multicolumn{2}{|c|}{$\begin{array}{l}<70 \\
\text { Years }\end{array}$} & \multicolumn{2}{|c|}{$\begin{array}{l}\geq 70 \\
\text { Years }\end{array}$} \\
\hline & No. & $\%$ & No. & $\%$ & No. & $\%$ & No. & $\%$ & No. & $\%$ & No. & $\%$ & No. & $\%$ & No. & $\%$ & No. & $\%$ \\
\hline$\leq 6$ & $124^{*}$ & 89 & $267^{*}$ & 90 & $349^{*}$ & 82 & 62 & 70 & 15 & 71 & 20 & 80 & 837 & 84 & 536 & 90 & 301 & 75 \\
\hline 7 & 13 & 9 & 21 & 7 & 64 & 15 & 25 & 27 & 5 & 23 & 4 & 16 & 132 & 13 & 45 & 8 & 87 & 22 \\
\hline Not available & 3 & 2 & 9 & 3 & 9 & 2 & 1 & 1 & 1 & 5 & 1 & 4 & 24 & 24 & 14 & 2 & 10 & 3 \\
\hline Total & 140 & & 297 & & 422 & & 88 & & 21 & & 25 & & 993 & & 595 & & 398 & \\
\hline
\end{tabular}




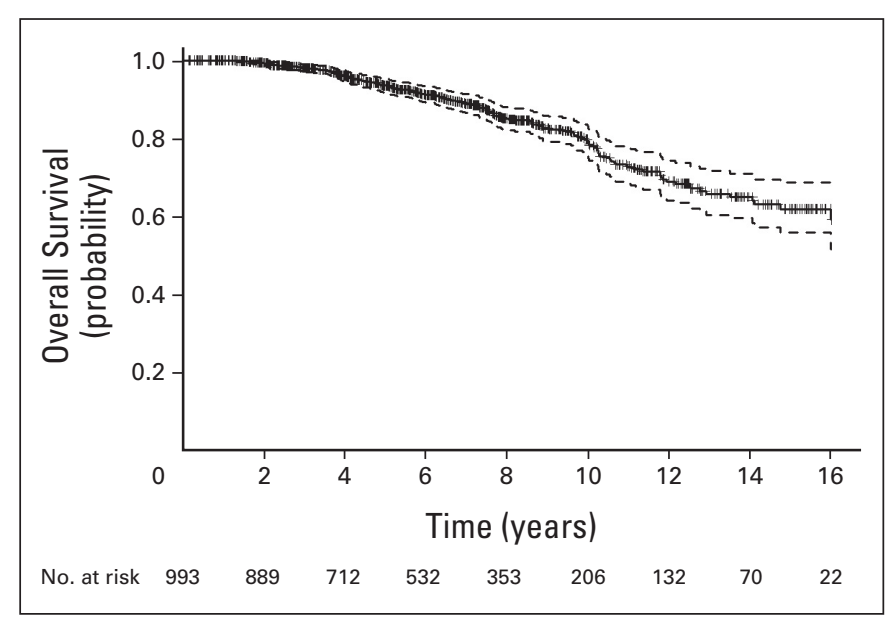

Fig 1. Kaplan-Meier overall survival curve with $95 \% \mathrm{Cls}$ in all patients.

Univariable analysis was used to determine which factors were associated with early development of metastasis. Those with a PSA DT of less than 3 years experienced progression earlier than the group with longer PSA DT (median, $5.12 v 9.23$ years, respectively; $P=.002$ ). The finding of a Gleason score of 8 to 10 on confirmatory biopsy was associated with early progression to metastasis (Gleason score of $6 v 8$, $P=.034$; Gleason score of $7 v 8, P=.023$ ).

The cumulative HR for non-prostate cancer to prostate cancer death in all patients was 9.2 (95\% CI, 5.4 to 15.6; Appendix Fig A2, online only). Appendix Figure A3 (online only) shows this HR stratified by age $\geq$ or less than 70 years. As expected, the risk of nonprostate cancer mortality was higher in men $\geq 70$ years old (HR, 11.5; $95 \%$ CI, 5.8 to 22.8), although even in men younger than age 70, the risk of non-prostate cancer mortality was almost six times higher than that of prostate cancer mortality (HR, 5.8; 95\% CI, 2.4 to 13.8).

\section{Intervention}

To date, 267 (27\%) of the 993 patients have been treated. Time to treatment is shown in Figure 3. At 5, 10, 15, and 20 years, 75.7\%, $63.5 \%, 55.0 \%$, and $55.0 \%$ of patients remain untreated and on surveillance, respectively. The reasons for discontinuing surveillance are listed in Table 2. PSA DT and grade of progression were the most

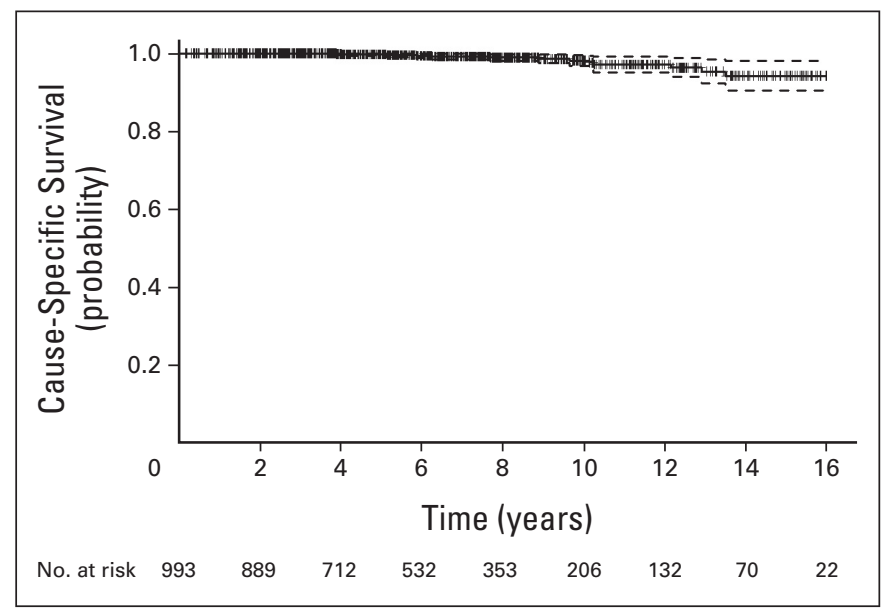

Fig 2. Kaplan-Meier cause-specific survival curve with $95 \% \mathrm{Cls}$ in all patients.

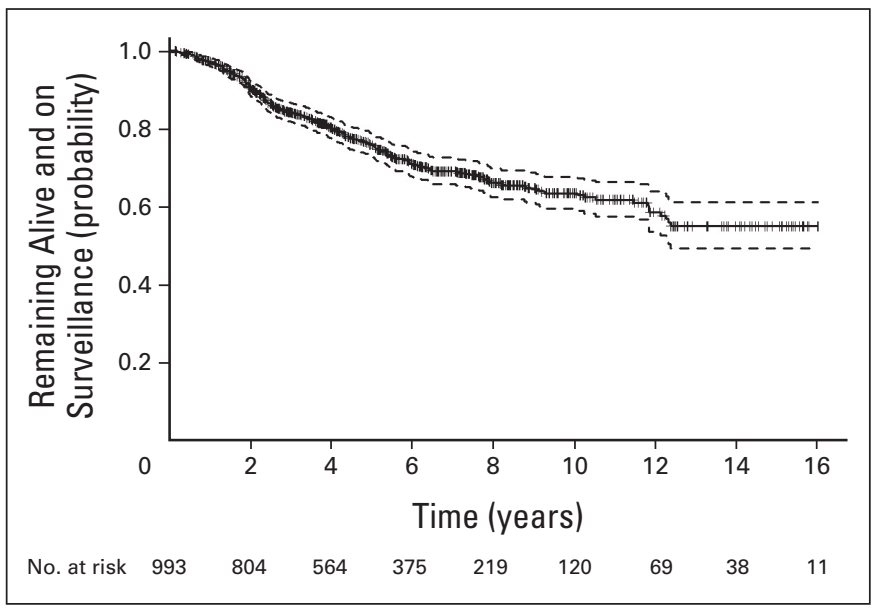

Fig 3. Time to intervention with $95 \% \mathrm{Cls}$ in all patients.

common reasons for starting treatment. The choice of RT, RP, or androgen-deprivation therapy was based on age, general health, and patient preference.

Appendix Table A2 (online only) shows the univariable and multivariable analysis of factors predicting for the likelihood of being reclassified as higher risk. Age, tumor stage ( $<v \geq \mathrm{T} 2)$, PSA values, Gleason score $(\leq v>6)$, number of cores involved at baseline and on confirmatory biopsy, and prostatitis on biopsy all correlated with risk reclassification. The likelihood of being treated was related to Gleason score $(P=.005$; odds ratio $[\mathrm{OR}], 1.72)$ and baseline tumor category $\geq \mathrm{T} 2 \mathrm{a}(P<.001$; OR, 1.96) but not to baseline PSA $(>v \leq 10 \mathrm{ng} / \mathrm{mL} ; P=.59)$ in the univariable analysis. In the multivariable analysis, Gleason score at 1 year $(P<.001)$ and baseline PSA values (log scale; $P=.046$ ) were significantly predictive for intervention. This final multivariable model showed no evidence of lack of fit based on the Hosmer-Lemeshow statistic $(P=.235)$. The probability of misclassification was $21.2 \%$.

Post-treatment PSA levels were available for 249 patients (93\%) treated after a period of surveillance, whereas the remaining 18 patients were treated elsewhere and post-treatment PSA levels could not be obtained. PSA failure has been calculated both from the date of diagnosis of prostate cancer, using the entire cohort as the denominator, and from the

\begin{tabular}{|lccc|}
\hline \multicolumn{4}{c}{ Table 2. Reasons for Intervention on Surveillance } \\
\hline $\begin{array}{l}\text { Reason for Intervention/ } \\
\text { Treatment }\end{array}$ & $\begin{array}{c}\text { No. of } \\
\text { Patients }\end{array}$ & $\begin{array}{c}\text { Treated Patients } \\
(\mathrm{n}=267)\end{array}$ & $\begin{array}{c}\text { Total Cohort } \\
(\mathrm{N}=993)\end{array}$ \\
\hline Short PSA doubling time & 116 & 43.5 & 11.7 \\
Grade progression & 94 & 35 & 9.5 \\
Patient preference & 16 & 6 & 1.6 \\
Stage progression & 8 & 3 & 0.8 \\
Biopsy volume progression & 6 & 2 & 0.6 \\
Ureteral obstruction & 3 & 1 & 0.3 \\
Ultrasound lesion volume & 1 & 0.4 & 0.1 \\
increase $>2 \times$ & 2 & 0.8 & 0.2 \\
Other & 21 & 7.9 & 2 \\
Not reported & 267 & 100 & 27 \\
Total & & & \\
\hline Abbreviation: PSA, prostate-specific antigen. & \\
\hline
\end{tabular}




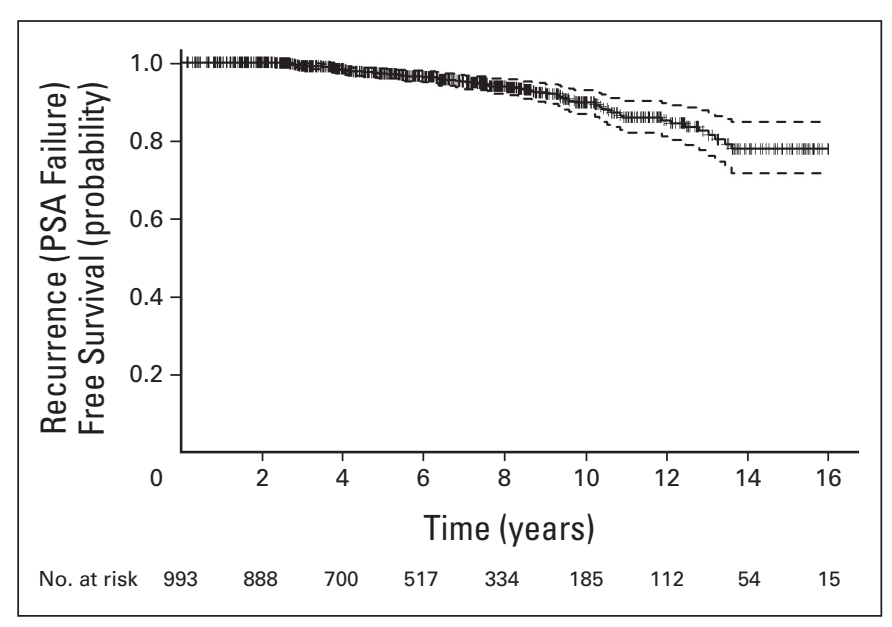

Fig 4. Time from diagnosis to prostate-specific antigen (PSA) failure (as proportion of all patients).

date of treatment using the treated patients as the denominator. Of the 249 patients, $63(25 \%)$ experienced a PSA failure, representing $6 \%$ of the overall cohort (63 of 993 patients). As a proportion of the entire surveillance cohort (Fig 4), the 5- and 10-year biochemical disease-free survival rates from the time of diagnosis were $97.2 \%$ and $89.8 \%$, respectively. The 5- and 10-year biochemical disease-free survival rates from the time of treatment as a proportion of the treated patients were $77 \%$ and $60 \%$, respectively (Appendix Fig A4, online only). Of the 75 patients treated with RP and 148 patients treated with RT, $25 \%$ and $24 \%$ experienced PSA failure, respectively. The biochemical no evidence of disease survival rates after RP at 5, 10, and 15 years from the date of treatment were $80 \%, 65 \%$, and 54\%, respectively; in patients treated with RT, the rates were 79\%, $60 \%$, and $48 \%$, respectively. This difference in biochemical no evidence of disease failure between RP and RT was not significant $(P=.60)$, notwithstanding the difference in definitions of PSA failure between these groups. The PSA failure rates in the treated patients at 5, 10, and $\geq 14$ years from the date of diagnosis as a proportion of the whole cohort were $3 \%, 10 \%$, and $22 \%$, respectively.

Appendix Table A3 lists the univariable and multivariable factors predicting for biochemical failure after intervention. Factors predicting for PSA failure were age, tumor stage, log PSA at baseline, baseline Gleason score, PSA DT, and percentage and number of cores involved on the initial biopsy. Neither the presence of prostatic intraepithelial neoplasia nor atypical small acinar proliferation predicted for biochemical failure after treatment. Biopsy findings were a trigger for intervention in $35 \%$ of the treated patients. However, number of biopsies, Gleason score, and number of cores involved on the biopsy triggering intervention were not significantly predictive for biochemical failure after treatment. Patients with longer duration of surveillance had a lower risk of biochemical failure after treatment $(\mathrm{OR}, 0.82$; $95 \% \mathrm{CI}, 0.74$ to 0.89 ). A PSA DT of less than 3 years was associated with a 7.8-fold (95\% CI, 4.4 to 13.7-fold) greater likelihood of biochemical recurrence after treatment compared with a PSA DT of $\geq 3$ years. Among patients with a PSA DT of less than 3 years, the absolute value of the DT (ie, 0 to 1,1 to 2 , or 2 to 3 years) was not predictive. In the multivariable analysis, duration of active surveillance $(P<.001)$ and baseline PSA values ( $\log$ scale; $P=.014$ ) were significantly predictive for PSA failure after definitive therapy. This final multivariable model showed no evidence of lack of fit based on the Hosmer-
Lemeshow statistic $(P=.902)$. The probability of misclassification was only $6.5 \%$.

\section{DISCUSSION}

Active surveillance has been increasingly accepted as a safe approach to favorable-risk prostate cancer in the 5- to 10-year time frame. In this series, follow-up is extended to 16 years. Two hundred six patients have been observed for more than 10 years and 60 patients for more than 15 years. The 10 - and 15-year actuarial CSS rates are $98.1 \%$ and $94.3 \%$, respectively. Only 15 patients in this cohort of 993 patients have died of prostate cancer, and an additional 13 patients have developed metastatic disease. The OS rate is $85.0 \%$. Younger patients were not at increased risk for prostate cancer mortality. Post hoc power analysis determined that our study achieved greater than $99 \%$ power to contrast the 15 -year prostate cancer mortality between $5.7 \%$ (Fig 2) in our study and $22 \%$ in the study by Albertsen et al. ${ }^{7}$

There are seven active surveillance series in the literature, including this one (Table 2), constituting more than 4,000 patients. ${ }^{3,8-12}$ OS in the combined cohort is $93 \%$, and the disease-specific survival is $99.7 \%$. One third of patients have been treated definitively. The data reported here extend the confidence regarding the indolent and nonlethal nature of most favorable-risk prostate cancer beyond 15 years.

Twenty-five percent of the patients in this study fulfilled the D'Amico criteria for intermediate risk. Nonetheless, the 15-year prostate cancer mortality is low. This supports the concept that in a screened population, selected men older than age 70 years with intermediate-risk prostate cancer are candidates for surveillance.

Popiolek et $\mathrm{al}^{13}$ reported prostate cancer mortality in lowgrade patients managed with watchful waiting (with no option of radical intervention) observed for more than 30 years. In the low-risk group, prostate cancer mortality was $13 \%$ overall and was $11 \%$ and $28 \%$ at 15 and 20 years, respectively. These patients, importantly, were not offered delayed definitive intervention. This likely explains the two-fold greater 15 -year prostate cancer mortality in the experience of Popiolek et al $^{13}$ compared with this active surveillance cohort (11\% v 5.7\%, respectively).

The PSA progression rates among the 249 evaluable patients offered definitive local therapy 5 and 10 years after the therapeutic intervention were $23 \%$ and $41 \%$, respectively. More meaningfully, the rates of all patients on surveillance who were treated and went on to experience subsequent PSA failure were $2.8 \%$ and $10.2 \%$ at 5 and 10 years after diagnosis, respectively. This is comparable to the outcome of radiation and surgery for favorable-risk disease.

A PSA DT of less than 3 years as the trigger for intervention was associated with a 7.8-fold greater risk of PSA progression after definitive therapy compared with patients with a PSA DT $\geq 3$ years (in whom grade progression was the usual indication for intervention). This supports the concept that a PSA DT of less than 3 years is a marker for aggressive disease. It demonstrates sensitivity but lacks specificity. ${ }^{14}$ We previously reported that in 300 men who remained on surveillance long term, none of whom had clinical or pathologic progression, 50\% had at least one trigger for intervention at some point during the follow-up period. ${ }^{15}$ Therefore, relying on PSA kinetics to determine who to treat would result in significant overtreatment.

The PSA failure rate of $25 \%$ in the treated patients at 10 years compares favorably with our previous report, where it was approximately 
$50 \%{ }^{3}$ That included many patients from the late 1990s. Because confirmatory biopsies were not mandatory until 2002, those men who were risk reclassified with higher-grade disease were diagnosed later. They were treated in most cases with 66 Gy of radiation, a dose that today is considered subtherapeutic, and were managed on surveillance in a period when experience with this approach was limited and decision making more ad hoc. Ten percent of the overall cohort experienced post-treatment PSA failure, consistent with PSA failure after radiation or surgery in a favorable-risk cohort. ${ }^{16,17}$ Furthermore, most of the surgically treated patients with PSA failure received effective salvage RT. Over 1,000 bootstrap samples, the SEs of coefficients for significant factors predicting for therapeutic intervention and for PSA failure after definitive therapy in the final multivariable models can be found in Appendix Tables A2 and A3. Compared with the original model estimates (SE) for those significant predictive factors in the multivariable analyses, the bias of estimator or SE was similar between the original SE and the bootstrapping SE for the two models. Therefore, the reproducibility of the models was confirmed. We conclude that these clinical parameters contributed significantly to the therapeutic intervention and to the PSA failure after treatment after validation by the bootstrap approach.

Active surveillance is an evolving strategy. The major limitation is that a significant proportion of patients diagnosed with Gleason score 6 cancer harbor higher-grade disease. The ability to identify earlier and more accurately those patients with occult Gleason pattern 4 and 5 cancer is likely to result in improved results, including a decrease in PSA failure rates in the risk-reclassified patients and lower metastasis and mortality rates. This would also offer reassurance to those patients not found to have higher-risk disease. Both multiparametric MRI and molecular biomarkers show promise in providing this opportunity. We and others have incorporated MRI into patient decision making. However, the cohort described here, 97\% of whom remained free of metastatic disease or prostate cancer mortality and 55\% of whom avoided any treatment, was largely managed without the benefit of MRI.
This study had some limitations. Patients were graded according to the Gleason grading system at the time of diagnosis. We did not perform International Society of Urological Pathology-standard regrading. Thus, many of the patients graded as Gleason score 6 during the period from 1996 to 2005 might be graded as Gleason score 7 using the modified Gleason system.

Active surveillance for favorable-risk and select early intermediaterisk prostate cancer is feasible and seems to be safe over 15 years. This strategy provides the benefit of a personalized approach based on the demonstrated risk of clinical or biochemical progression with time. In this cohort, the likelihood of dying of other causes was 9.2 times greater than the likelihood of prostate cancer death. Although prostate cancer mortality increased with longer followup, only $2.8 \%$ of patients have developed metastatic disease and $1.5 \%$ have died of prostate cancer. These findings are consistent with expected mortality in favorable-risk patients managed with initial definitive intervention.

\section{AUTHORS' DISCLOSURES OF POTENTIAL CONFLICTS OF INTEREST}

Disclosures provided by the authors are available with this article at www.jco.org.

\section{AUTHOR CONTRIBUTIONS}

Conception and design: Laurence Klotz, Danny Vesprini, Andrew

Loblaw

Collection and assembly of data: Laurence Klotz, Perakaa Sethukavalan,

Vibhuti Jethava, Suneil Jain, Toshihiro Yamamoto, Alexandre Mamedov, Andrew Loblaw

Data analysis and interpretation: Laurence Klotz, Danny Vesprini,

Liying Zhang, Suneil Jain, Andrew Loblaw

Manuscript writing: All authors

Final approval of manuscript: All authors

\section{REFERENCES}

1. Choo R, Klotz L, Danjoux C, et al: Feasibility study: Watchful waiting for localized low to intermediate grade prostate carcinoma with selective delayed intervention based on prostate specific antigen, histological and/or clinical progression. J Urol 167:1664-1669, 2002

2. Klotz L: Active surveillance for prostate cancer: For whom? J Clin Oncol 23:8165-8169, 2005

3. Klotz $L$, Zhang $L$, Lam $A$, et al: Clinical results of long-term follow-up of a large, active surveillance cohort with localized prostate cancer. J Clin Oncol 28:126-131, 2010

4. Remzi M, Fong YK, Dobrovits $\mathrm{M}$, et al: The Vienna nomogram: Validation of a novel biopsy strategy defining the optimal number of cores based on patient age and total prostate volume. J Urol 174:1256-1260, 2005

5. Altman DG, De Stavola BL, Love $S B$, et al: Review of survival analyses published in cancer journals. Br J Cancer 72:511-518, 1995

6. Zhang L, Loblaw A, Klotz L: Modeling prostate specific antigen kinetics in patients on active surveillance. J Urol 176:1392-1397, 2006
7. Albertsen PC, Hanley JA, Fine J: 20-year outcomes following conservative management of clinically localized prostate cancer. JAMA 293:20952101, 2005

8. van As NJ, Norman AR, Thomas $K$, et al: Predicting the probability of deferred radical treatment for localised prostate cancer managed by active surveillance. Eur Urol 54:1297-1305, 2008

9. Carter HB, Kettermann A, Warlick $C$, et al: Expectant management of prostate cancer with curative intent: An update of the Johns Hopkins experience. J Urol 178:2359-2364, 2007

10. Soloway MS, Soloway CT, Williams $S$, et al: Active surveillance: $\mathrm{A}$ reasonable management alternative for patients with prostate cancer-The Miami experience. BJU Int 101:165-169, 2008

11. Roemeling S, Roobol MJ, de Vries SH, et al: Active surveillance for prostate cancers detected in three subsequent rounds of a screening trial: Characteristics, PSA doubling times, and outcome. Eur Urol 51:1244-1250, 2007

12. Khatami A, Aus G, Damber JE, et al: PSA doubling time predicts the outcome after active surveillance in screening-detected prostate cancer: Results from the European randomized study of screening for prostate cancer, Sweden section. Int J Cancer 120:170-174, 2007

13. Popiolek M, Rider JR, Ondren O, et al: Natural history of early localized prostate cancer: A final report from three decades of follow up. Eur Urol 63:428-435, 2013

14. Vickers AJ, Savage C, O'Brien MF, et al: Systematic review of pretreatment prostatespecific antigen velocity and doubling time as predictors for prostate cancer. J Clin Oncol 27: 398-403, 2009

15. Loblaw A, Zhang L, Lam A, et al: Comparing prostate specific antigen triggers for intervention in men with stable prostate cancer on active surveillance. J Urol 184:1942-1946, 2010

16. Kane $\mathrm{CJ}$, Im R, Amling $\mathrm{CL}$, et al: Outcomes after radical prostatectomy among men who are candidates for active surveillance: Results from the SEARCH database. Urology 76:695-700, 2010

17. Lukka H, Hayter C, Julian JA, et al: Randomized trial comparing two fractionation schedules for patients with localized prostate cancer. J Clin Oncol 23:6132-6138, 2005

18. Efron B: Bootstrap methods: Another look at the jackknife. Ann Statist 7:1-26, 1979 
active surveillance: an approach to management of suspected or proven malignancy felt to pose a low risk of progression in the short to intermediate term. Tumors are observed closely with blood tests, imaging, and/or serial biopsy, and intervention is undertaken if/when there is evidence of tumor growth or progression.

\section{Now Available: ASCO-SEP 4th Edition: The Essential Oncology Study Resource}

The 4th edition of ASCO-SEP is now available. This comprehensive resource is designed to assess your knowledge in various areas of oncology and provide the most up-to-date understanding of cancer, its treatment, and the supportive care needed to optimize care and the quality of life for people with cancer.

Learning formats include:

- Book/eBook: Includes 21 fully updated chapters and accompanying questions that cover all aspects of cancer care.

- Online Question Bank: Provides an additional 100 bonus questions, in addition to those found in the book/eBook.

- NEW! MOC Course: Consists of 60 multiple-choice questions for a total of 20 Medical Knowledge MOC points.

- ASCO Flashcards: ASCO-SEP: Includes 200 flashcards with questions designed to provide short but helpful bursts of education.

ASCO members save 20\%. Learn more at university.asco.org/SEP. 


\section{AUTHORS' DISCLOSURES OF POTENTIAL CONFLICTS OF INTEREST}

\section{Long-Term Follow-Up of a Large Active Surveillance Cohort of Patients With Prostate Cancer}

The following represents disclosure information provided by authors of this manuscript. All relationships are considered compensated. Relationships are self-held unless noted. I = Immediate Family Member, Inst = My Institution. Relationships may not relate to the subject matter of this manuscript. For more information about ASCO's conflict of interest policy, please refer to www.asco.org/rwc or jco.ascopubs.org/site/ifc.

\section{Laurence Klotz}

No relationship to disclose

Danny Vesprini

No relationship to disclose

Perakaa Sethukavalan

No relationship to disclose

Vibhuti Jethava

No relationship to disclose

Liying Zhang

No relationship to disclose

Suneil Jain

No relationship to disclose

Toshihiro Yamamoto

No relationship to disclose

Alexandre Mamedov

No relationship to disclose

Andrew Loblaw

No relationship to disclose 


\section{Appendix}

\begin{tabular}{|c|c|c|c|c|c|c|}
\hline \multirow[b]{3}{*}{ Clinical Tumor Stage at Baseline } & & & & & & \\
\hline & \multicolumn{2}{|c|}{ Total Patients } & \multicolumn{2}{|c|}{$<70$ Years } & \multicolumn{2}{|c|}{$\geq 70$ Years } \\
\hline & No. & $\%$ & No. & $\%$ & No. & $\%$ \\
\hline T1a & 17 & 1.7 & 12 & 2.0 & 5 & $\overline{1.2}$ \\
\hline $\mathrm{T} 1 \mathrm{~b}$ & 31 & 3.1 & 17 & 2.9 & 14 & 3.5 \\
\hline T1c & 739 & 74. & 462 & 77.5 & 277 & 69.6 \\
\hline T2 & 3 & 0.3 & 2 & 0.3 & 1 & 0.2 \\
\hline $\mathrm{T} 2 \mathrm{a}$ & 126 & 12.7 & 61 & 10.2 & 65 & 16.3 \\
\hline $\mathrm{T} 2 \mathrm{~b}$ & 25 & 2.5 & 8 & 1.3 & 17 & 4.2 \\
\hline $\mathrm{T} 2 \mathrm{C}$ & 15 & 1.5 & 7 & 1.1 & 8 & 2.0 \\
\hline Unknown & 37 & 3.7 & 26 & 4.3 & 11 & 2.7 \\
\hline Total & 993 & & 595 & & 398 & \\
\hline
\end{tabular}

Table A2. Univariable and Multivariable Logistic Regression Analysis of Factors Predicting for Therapeutic Intervention and Comparing Final Multivariable Mode Estimations on SE of Predictive Factors Using the Original Data and 1,000 Bootstrapping Samples

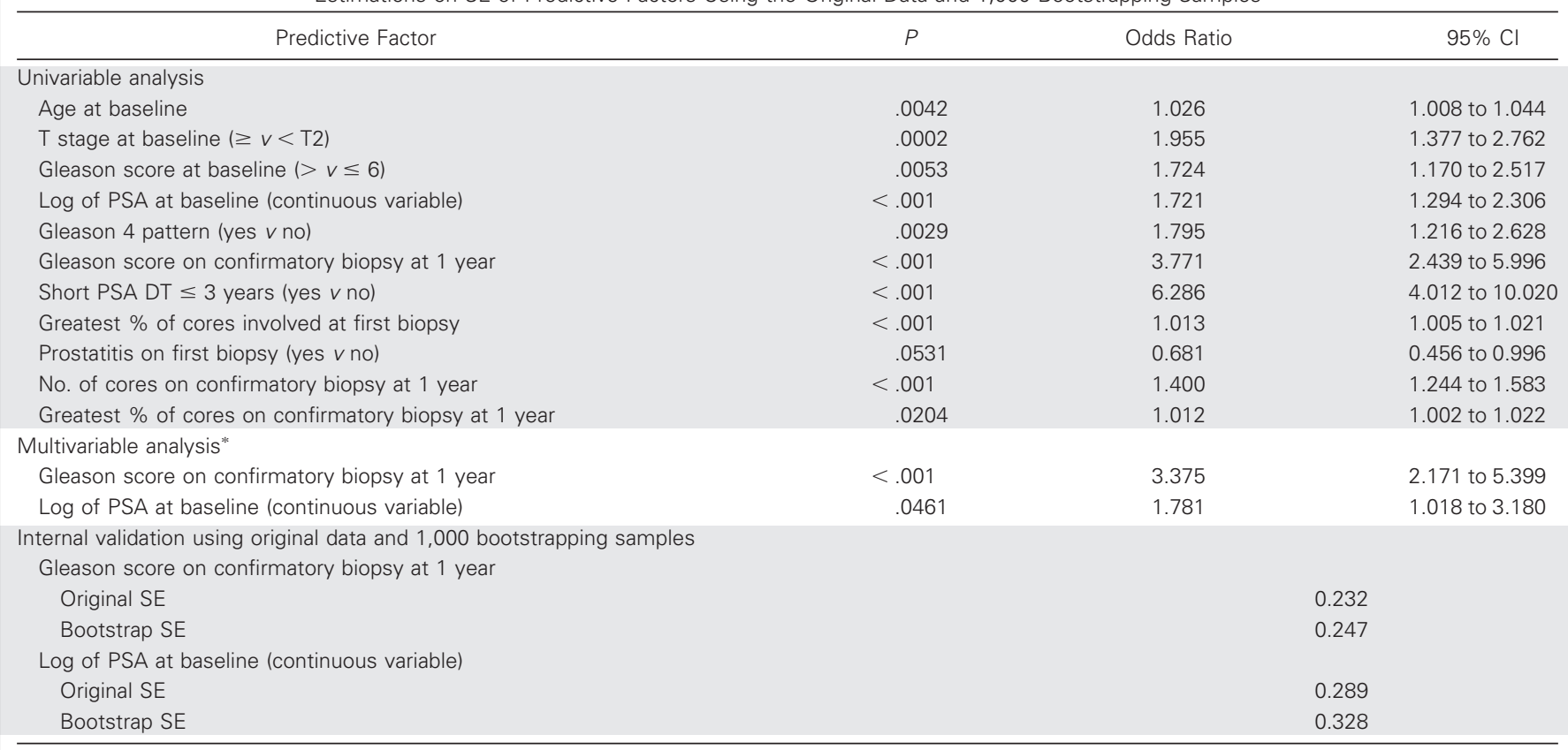

Abbreviation: DT, doubling time; PSA, prostate-specific antigen.

"Short PSA DT $\leq 3$ years was excluded in the multivariable logistic regression analysis because it was a criteria for treatment. 


\begin{tabular}{|c|c|c|c|}
\hline Variable & $P$ & Odds Ratio & $95 \% \mathrm{Cl}$ \\
\hline \multicolumn{4}{|l|}{ Univariable analysis } \\
\hline T stage at baseline $(\geq v<\mathrm{T} 2)$ & .0085 & 2.139 & 1.190 to 3.714 \\
\hline Log of PSA at baseline (continuous variable) & .0109 & 1.999 & 1.185 to 3.444 \\
\hline Gleason score at baseline & .3174 & 1.279 & 0.774 to 2.022 \\
\hline Gleason score before intervention & .9902 & 0.998 & 0.698 to 1.413 \\
\hline No. of biopsies & .7571 & 1.043 & 0.793 to 1.349 \\
\hline Short PSA DT $\leq 3$ years (yes $v$ no) & $<.001$ & 7.801 & 4.393 to 13.667 \\
\hline Duration on active surveillance (years) & $<.001$ & 0.817 & 0.738 to 0.894 \\
\hline No. of cores involved on confirmatory biopsy at first time & .1356 & 1.070 & 0.962 to 1.162 \\
\hline No. of cores involved before intervention & .8792 & 0.996 & 0.918 to 1.036 \\
\hline \multicolumn{4}{|l|}{ Multivariable analysis* } \\
\hline Duration of active surveillance & $<.001$ & 0.809 & 0.730 to 0.887 \\
\hline Log of PSA at baseline (continuous variable) & .0140 & 1.945 & 1.156 to 3.344 \\
\hline \multicolumn{4}{|c|}{ Internal validation using original data and 1,000 bootstrapping samples } \\
\hline \multicolumn{4}{|c|}{ Duration of active surveillance } \\
\hline Original SE & & \multicolumn{2}{|c|}{0.050} \\
\hline Bootstrap SE & & \multicolumn{2}{|c|}{0.051} \\
\hline \multicolumn{4}{|l|}{ Log of PSA at baseline (continuous variable) } \\
\hline Original SE & & \multicolumn{2}{|c|}{0.271} \\
\hline Bootstrap SE & & \multicolumn{2}{|c|}{0.252} \\
\hline
\end{tabular}

Abbreviation: DT, doubling time; PSA, prostate-specific antigen.

"Short PSA DT $\leq 3$ years was excluded in the multivariable logistic regression analysis because it was a criteria for treatment.

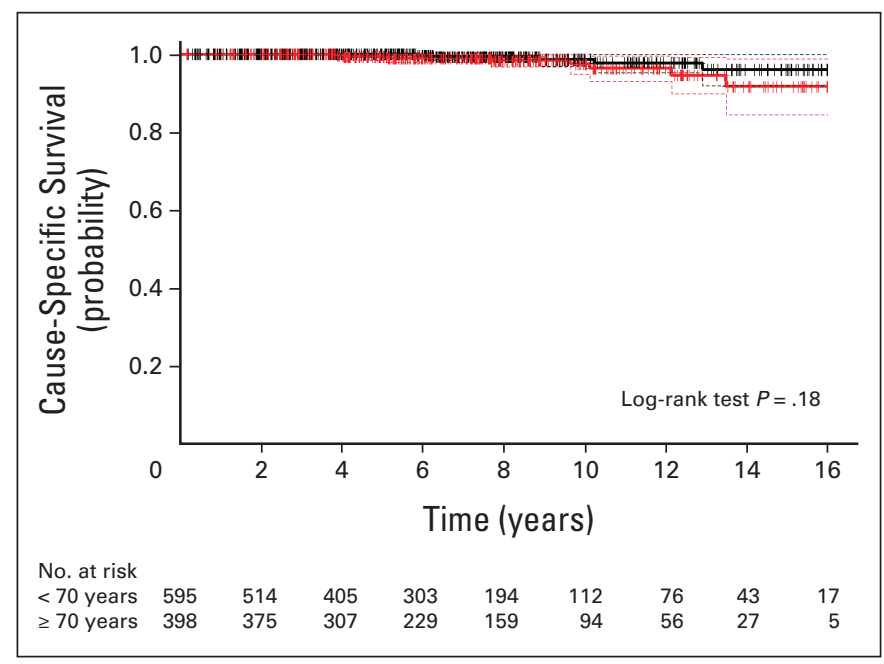

Fig A1. Kaplan-Meier cause-specific survival curves stratified by age less than or $\geq 70$ years (log-rank test, $P=.13$ ) 


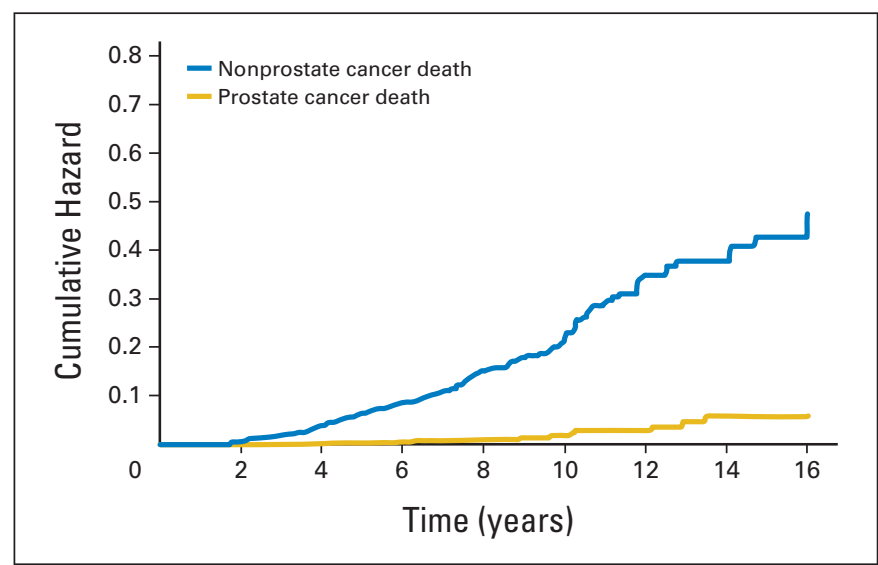

Fig A2. Cumulative hazard ratio of non-prostate cancer death (blue line) to prostate cancer death (gold line).

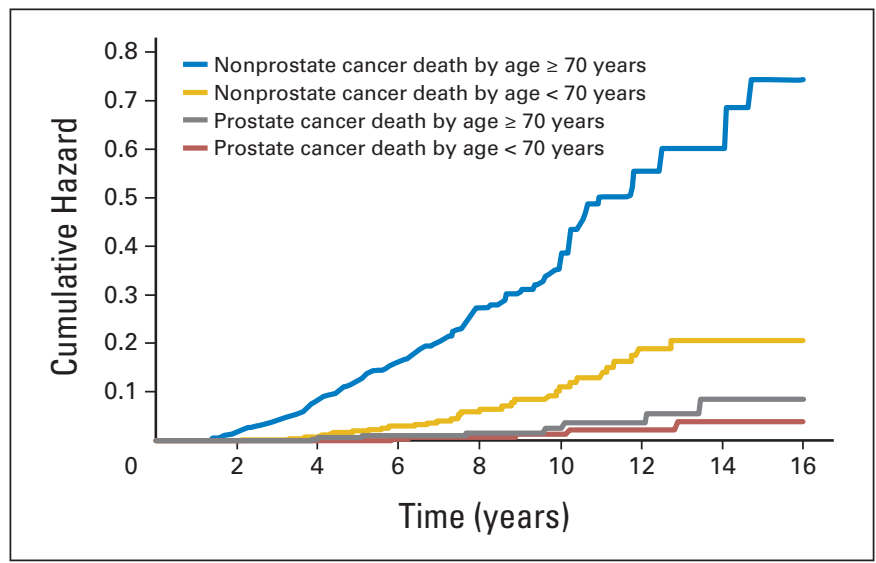

Fig A3. Cumulative hazard of non-prostate cancer death stratified by age $\geq 70$ years (blue line) or by age less than 70 years (gold line) and of prostate cancer death stratified by age $\geq 70$ years (gray line) or by age less than 70 years (red line).

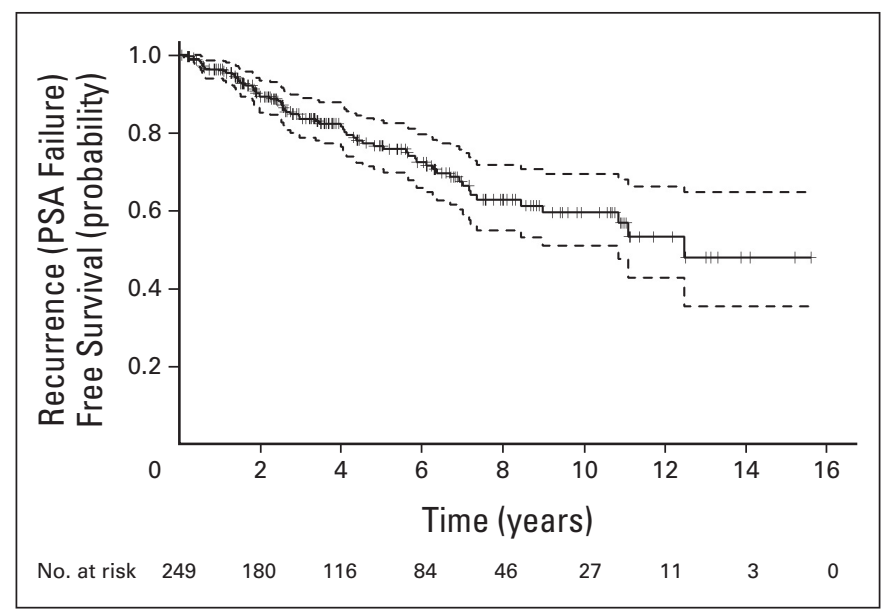

Fig A4. Time from treatment to prostate-specific antigen (PSA) failure (treated patients only). 